\title{
Sample taking problems in measuring actual histamine levels of human gastroduodenal mucosa: specific and general relevance in clinical trials on peptic ulcer pathogenesis and selective proximal vagotomy
}

\author{
K P THON, W LORENZ, Ch OHMANN, D WEBER, H ROHDE, AND H D RÖHER \\ From the Surgical Clinic and Department of Theoretical Surgery, Centre of Operative Medicine I, University \\ of Marburg/Lahn, FRG
}

SUMmARY Changes in histamine storage in the oxyntic mucosa of duodenal ulcer patients and their reversal by vagotomy and the histamine $\mathrm{H}_{2}$-antagonist cimetidine supported the hypothesis that histamine could be a causal factor in peptic ulcer pathogenesis. The specificity of these findings was impaired by problems in biopsy taking, however, and in the preparative steps before measuring the actual histamine contents in all parts of the gastric mucosa and in the duodenum. A prospective trial was carried out in 190 patients to identify these sources of bias and to overcome them by appropriate study designs. ${ }^{1}$ Usually a direct correlation was found between weight of biopsy and mucosal histamine content. This problem was solved by selecting a biopsy forceps producing smaller variations in sample size, by limiting the time of cold ischaemia to four to five minutes only and by taking three biopsy specimens for each single histamine value. ${ }^{2}$ The actual histamine content of mucosal biopsies remained constant for about four to five minutes only. The 'disappearance' rate was faster in control subjects than in duodenal ulcer patients. Hence by variation of the cold ischaemia time any artefacts of differences between mucosal histamine levels in controls and duodenal ulcer patients could be produced. ${ }^{3}$ Using the optimised sample taking procedure mucosal histamine contents of several gastric regions and the duodenal bulb were measured in 24 patients with duodenal ulcer, after selective proximal vagotomy without drainage and in control subjects without any stomach disease (randomised controlled trial). The histamine content was lower in all parts of the upper gastrointestinal tract in duodenal ulcer patients than in controls and was raised again in all regions after selective proximal vagotomy. As the most likely hypothesis it is suggested that vagal reflexes with 'afferent fibres coming from the oxyntic mucosa stimulate histamine release in duodenal ulcer patients by efferent peptidergic neurones to all parts of the stomach and the duodenum where the ulcer lesion is situated.

A series of congruous findings in the last decade ${ }^{1-8}$ supports the hypothesis that histamine is a causal factor (contributory condition or even sufficient determinant $\left.{ }^{9}\right)$ in duodenal ulcer pathogenesis. Fun$\operatorname{dic}^{6}$ and corpus ${ }^{15}$ mucosal histamine content and histamine methyltransferase activity 67910 are decreased in patients with chronic duodenal ulcer as

Address for correspondence: Klaūs Thon, MD, Surgical Clinic, Centre of Operative Medicine I, Philipps-University of Marburg, Boldingerstrasse, 3550 Marburg (Lahn), Federal Republic of Germany.

Received for publication 20 December 1984 compared with those subjects with normal clinical and endoscopical findings in stomach and duodenum. These alterations are reversed in patients after adequate selective vagotomy ${ }^{210}$ and cimetidine treatment ${ }^{5}$ but not in those with Hollanderincomplete vagotomy ${ }^{2}$ and with recurrent ulceration both after gastric and selective proximal vagotomy. ${ }^{25} 10$ The mucosal histamine content after selective vagotomy and pyloroplasty is inversely correlated to the residual peak acid output and directly proportional to its reduction. ${ }^{3}$

In order to establish histamine as a pathogenetic 
factor in peptic ulcer disease, however, specificity of all these changes and associations is a vital criterion which has many dimensions. Most of which are not investigated thoroughly enough or even are a matter of considerable debate because histamine is only one candidate among so many active substances ${ }^{11}$ which are claimed to be involved in peptic ulcer disease. The criteria include (a) specificity of the fluorometric and radio-enzymatic assays in most common gastric diseases and after medical treatment, ${ }^{2} 37^{12-15}$ (b) that of sample taking ${ }^{36-18}$ and of the reference systems (wet weight, tissue protein and DNA), (c) specificity with regard to the patient's attributes (age, sex, additional genetic and environmental factors, smoking, alcohol and drugs $^{1-71920}$ ) and the status of health and disease (return of the values to 'normal' after healing the ulcer), (d) specificity of the alterations with regard to the topographical distribution (oxyntic mucosa, duodenum) and finally (e) the specificity of interpreting the decrease of mucosal histamine unequivocally as histamine release. ${ }^{2} 381521$

Two of these problems in specificity are the subject of this communication: sample taking and regional distribution. Preliminary reports were given at the European Gastro $\mathrm{Club}^{22}$ and the German Surgical Society. ${ }^{23}$

\section{Methods}

\section{MATERIALS}

This series of prospective trials was carried out in 190 German patients of the Surgical Clinic, Marburg/Lahn from 1973 to 1983 by five endoscopists, two technicians and one coordinator who remained throughout. The seven series of the study were conducted with relatively long lasting intervals as we became only gradually aware of the numerous problems associated with sample taking of mucosal biopsies. $^{2}{ }^{3}{ }^{16-18}$ The attributes of the patients were compiled in detail in Table 1 except those from 126 subjects from whom only the frequency distributions of biopsy weights were reported (Fig. 1).

Biopsy specimens were removed from all the patients in study who had fasted overnight, during routine endoscopy from $0830 \mathrm{am}-1200$ noon. A panendoscope 7089 P (ACMI, Wappler, Munich) was used in the first 136 subjects, ${ }^{16}$ an Olympus endoscope GIF-Q with the 'hot biopsy' forceps FD-12 in the remaining 54 patients.

As soon as the final diagnosis was established by clinical and endoscopical findings four to 11 specimens were withdrawn from the middle of the corpus region at the greater curvature. ${ }^{16}$ During stepwise biopsy taking, however, in the controlled clinical trial (no 7) additionally four mucosal specimens

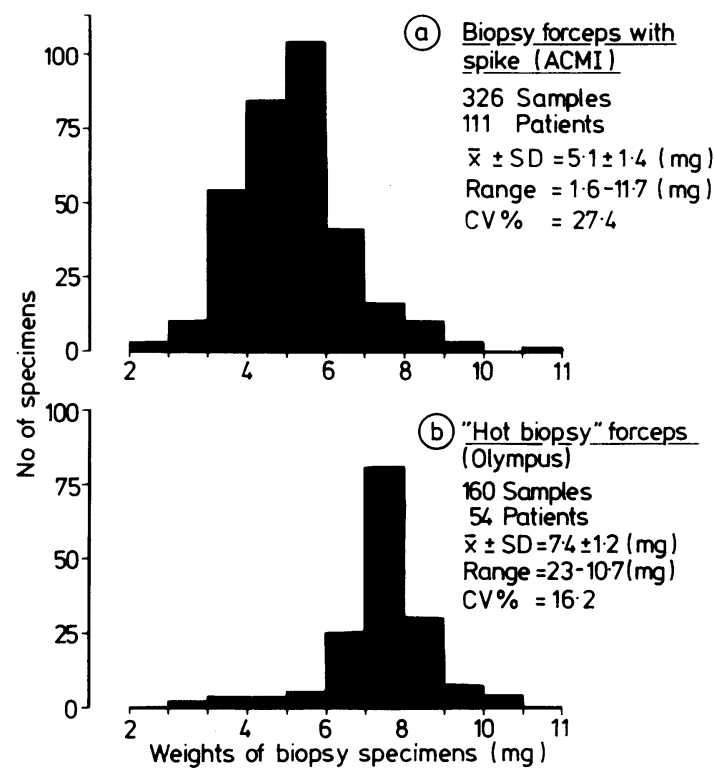

Fig. 1 Frequency distributions of biopsy weights obtained with two different types of biopsy forceps. Single values obtained from three specimens of an individual patient. A few samples were lost (seven in series $a$, two in series $b$ ). In the two trials only two endoscopists were involved in sample taking. For further conditions see Materials and Methods.

were removed from the fundus (paracardially at the greater curvature), from the antrum $(2-5 \mathrm{~cm}$ orally from the pylorus again at the greater curvature) and from the duodenum (middle of the bulb at the lesser curvature). From each gastric region one biopsy was used for microscopical examination.

The mucosal specimens were placed on hard filter paper (Whateman No 2) in a petri dish which was moistened with a few drops of Ringer solution, were weighed on an analytical microbalance (Sartorius type 2774 in 1973, and then Mettler, type H-20 T) within no more than five minutes after withdrawal or after defined points of time in the corresponding experiments and were each suspended in $2 \mathrm{ml} 1 \mathrm{M}$ $\mathrm{HC} 0_{4}$. These mixtures were kept at $-20^{\circ} \mathrm{C}$ in a deep freezer for no longer than two weeks before histamine determination.

The same drugs and reagents for histamine assay were used as described by Rohde et al. ${ }^{16}$ Usually, however, no premedication was necessary in the patients. Some of them asked for a local anaesthetic spray (xylocaine), only three in 1983 received the previously used premedication, ${ }^{16}$ but all of the subjects drank 1-2 ml SAB-Simplex ${ }^{\circledR}$ (Parke-Davis) in about $30 \mathrm{ml}$ tap water. Most of the patients were admitted to hospital in the precimetidine era, but 
Table 1 Details of patients

\begin{tabular}{|c|c|c|c|c|c|c|c|c|c|c|c|c|c|}
\hline No & Initials & $\begin{array}{l}\text { Patie } \\
\text { Sex }\end{array}$ & $\begin{array}{l}n t s \\
\text { Age }\end{array}$ & Diagn & Concomitant dis & $\begin{array}{l}\text { Date of } \\
\text { endoscopy }\end{array}$ & No & Initials & $\begin{array}{l}\text { Patie } \\
\text { Sex }\end{array}$ & Age & Diagn & Concomitant dis & $\begin{array}{l}\text { Date of } \\
\text { endoscopy }\end{array}$ \\
\hline 1 & NK & $\mathbf{M}$ & 80 & UV(J1) & None & 23.6 .76 & 35 & WA & $\mathrm{F}$ & 67 & CS & None & 8.2 .83 \\
\hline 2 & $\mathrm{LCh}$ & $\mathrm{F}$ & 75 & CS & None & 7.7 .76 & 36 & $\mathrm{BM}$ & $\mathbf{M}$ & 51 & UD & Adipositas & 9.2 .83 \\
\hline 3 & SchE & $\mathbf{M}$ & 52 & CS & None & 7.7 .76 & & & & & & per-magna, Bypass & \\
\hline 4 & PA & $F$ & 50 & UD & None & 12.7 .76 & & & & & & op, renal calc. & \\
\hline \multirow[t]{2}{*}{5} & $\mathrm{CPh}$ & $\mathbf{M}$ & 68 & UV(J1) & Coronary insuff, & 15.7 .76 & 37 & BP & $\mathbf{M}$ & 71 & CS & None & 9.2 .83 \\
\hline & & & & & Diabetes, gout & & 38 & SW & $\mathbf{M}$ & 45 & SPV & None & 22.2 .83 \\
\hline 6 & DKH & $\mathbf{M}$ & 29 & CS & Cholelithiasis & 19.7 .76 & 39 & $\mathrm{FH}$ & $\mathbf{M}$ & 23 & CS & None & 1.3 .83 \\
\hline 7 & FB & M & 50 & CS & Cholelithiasis & 20.7 .76 & 40 & $\mathrm{KI}$ & $\mathrm{F}$ & 53 & UD & None & 16.3 .83 \\
\hline 8 & EF & $\mathbf{M}$ & 55 & CS & Bronchial carc. & 20.7 .76 & 41 & WK & $\mathrm{F}$ & 42 & $\mathrm{CS}$ & None & 17.3 .83 \\
\hline 9 & EE & $\mathrm{F}$ & 40 & CS & None & 21.7 .76 & 42 & Sch A & $\mathrm{F}$ & 55 & UD & None & 22.3 .83 \\
\hline 10 & $\mathrm{PE}$ & $\mathbf{M}$ & 46 & UD & None & 21.7 .76 & 43 & LL & $\mathbf{M}$ & 60 & UD & $\mathrm{Ca}$ of the tongue & 28.3 .83 \\
\hline 11 & JJ & $\mathbf{M}$ & 71 & $\mathrm{CA}$ & None & 2.8 .76 & 44 & $\mathrm{BH}$ & $\mathbf{M}$ & 50 & SPV & Herniated disc & 29.3 .83 \\
\hline 12 & HM & $\mathbf{F}$ & 67 & $\mathrm{CS}$ & Diabetes & 2.8 .76 & 45 & BK & $F$ & 71 & SPV & None & 5.4 .83 \\
\hline 13 & GA & $F$ & 67 & UD & Coronary insuff. & 2.8 .76 & 46 & $\mathrm{HH}$ & $\mathbf{M}$ & 50 & CS & None & 19.4 .83 \\
\hline 14 & SchH & $\mathbf{M}$ & 58 & CS & Cytogenic epilepsy & 2.8 .76 & 47 & $\mathrm{KE}$ & M & 50 & SPV & None & 19.4 .83 \\
\hline 15 & ZO & M & 44 & CA & None & 6.8 .76 & 48 & $\mathrm{HH}$ & M & 40 & SPV & None & 20.4 .83 \\
\hline 16 & GS & $F$ & 80 & $\mathrm{CA}(\mathrm{BII})$ & None & 9.8 .76 & 49 & GA & M & 60 & CS & None & 13.5 .83 \\
\hline 17 & HK & $\mathbf{M}$ & 44 & UD & None & 9.8 .76 & 50 & LJ & $\mathbf{M}$ & 59 & $\mathrm{CS}$ & None & 5.7 .83 \\
\hline 18 & WJ & $\mathbf{M}$ & 25 & CS & Alcoholism & 9.8 .76 & 51 & EJ & $\mathbf{M}$ & 51 & UD & None & 6.7 .83 \\
\hline 19 & $\mathrm{CS}$ & $\mathbf{M}$ & 33 & UD & None & 13.8 .76 & 52 & $\mathrm{AH}$ & M & 62 & $\mathrm{CS}$ & Oesophagitis II, & 6.7 .83 \\
\hline \multirow[t]{2}{*}{20} & FK & $\mathbf{M}$ & 54 & CS & Cholelithiasis, & 25.8 .76 & & & & & & cholelithiasis & \\
\hline & & & & & Hypertension & & 53 & StM & $\mathrm{F}$ & 45 & $\mathrm{CS}$ & None & 2.8 .83 \\
\hline 21 & $\mathrm{KF}$ & $\mathbf{M}$ & 62 & UV(J1) & Coronary insuff. & 31.8 .76 & 54 & $\mathrm{BM}$ & $\mathrm{F}$ & 72 & CS & None & 3.8 .83 \\
\hline 22 & KA & M & 63 & UV(J2) & None & 31.8 .76 & 55 & BR & M & 71 & UD & Oesophagitis II & 5.8 .83 \\
\hline 23 & BV & $\mathbf{M}$ & 41 & $\mathrm{CS}$ & None & 31.8 .76 & 56 & FH & $\mathbf{M}$ & 44 & $\mathrm{CS}$ & None & 9.8 .83 \\
\hline 24 & $\mathrm{BF}$ & $\mathbf{M}$ & 47 & UD & None & 31.8 .76 & 57 & SchM & $F$ & 64 & UV(J1) & None & 9.8 .83 \\
\hline 25 & ThH & $\mathbf{M}$ & 71 & CS & None & 31.8 .76 & 58 & EK & $\mathbf{M}$ & 58 & UD & Obstructive vascular & 10.8 .83 \\
\hline 26 & DF & $\mathbf{M}$ & 59 & UD & None & 1.2 .83 & & & & & & disease & \\
\hline 27 & MKH & $\mathbf{M}$ & 46 & SPV & Cholelithiasis & 2.2 .83 & 59 & MHD & M & 27 & SPV,RUD & None & 15.8 .83 \\
\hline 28 & ML & $\mathbf{M}$ & 64 & UD & None & 2.2 .83 & 60 & SchK & $\mathbf{M}$ & 74 & UD & Adipositas & 15.8 .83 \\
\hline 29 & EB & M & 22 & CS & None & 3.2 .83 & & & & & & per-magna & \\
\hline 30 & KR & $\mathbf{M}$ & 38 & UD & Alcoholism & 7.2 .83 & & & & & & Hypertension, MI & \\
\hline 31 & LHH & M & 39 & CS & Hyperplasia papillae & 7.2 .83 & 61 & $\mathrm{ZW}$ & $\mathbf{M}$ & 86 & UD & None & 30.8 .83 \\
\hline 32 & CS & M & 34 & SPV & None & 8.2 .83 & 62 & GM & $\mathrm{F}$ & 47 & UD & None & 31.8 .83 \\
\hline 33 & $\mathrm{JJ}$ & M & 34 & SPV & None & 8.2 .83 & 63 & KJ & $\mathbf{M}$ & 50 & $\mathrm{CS}$ & None & 5.9 .83 \\
\hline 34 & SchM & $\mathrm{F}$ & 59 & UD & None & 8.2 .83 & 64 & BKH & $\mathbf{M}$ & 69 & UD & None & 5.9 .83 \\
\hline
\end{tabular}

For allocation of patients to the various parts of this communication see study designs. Abbreviations starting from top left: $M=$ male, $\mathrm{F}=$ female, UV=gastric ulcer, J1,2=gastric ulcer, type Johnson I and II, SPV=selective proximal vagotomy, CS=control subjects, $\mathrm{UD}=$ duodenal ulcer, $\mathrm{RUD}=$ recurrent duodenal ulcer, $\mathrm{CA}=$ gastric carcinoma, $(\mathrm{BII})=$ after Billroth $\mathrm{II}$ resection, oesophagitis $\mathrm{II}=\mathrm{reflux}$ oesophagitis, grade II according to Savrany-Miller, MI=myocardial infarction.

those in 1983 were asked to stop medical treatment for peptic ulcer, except low doses of antacids, for two days before endoscopy, because cimetidine and ranitidine interfere with the histamine assays (Lorenz, unpublished data), alter histamine storage ${ }^{5}$ and metabolism, ${ }^{8}$ and pirencepine inhibits human gastrointestinal diamine oxidase. ${ }^{24}$

\section{EXPERIMENTAL DESIGNS}

\section{Relationship between weight of biopsy and} mucosal histamine content

In this part of the study four series of experiments were conducted from 1973 to 1983 .

(1) Biopsy specimens from corpus mucosa of 111 patients, ${ }^{12}$ three from each subject, were taken between April and September 1973, and weighed on a Sartorius microbalance. The dispersion of the specimen sizes was investigated by plotting the frequency distribution of the weights.

(2) The large variation in biopsy weights and its influence on the depth of sample taking from the corpus mucosa by the ACMI biopsy forceps ${ }^{16}$ induced the second series of experiments in nine patients (nos 1-9 in Table 1) in 1976. This studied the relationship between the weight of biopsy and its mucosal histamine content. Eleven specimens were taken from six control subjects with a healthy upper gastrointestinal tract, but some of them with concomitant diseases influencing tissue histamine levels ${ }^{25}$ and from three patients with peptic ulcer. The time of cold ischaemia (from withdrawal of mucosa by the scissors of the forceps via placing the particles in the petri dish, transport to the weighing room and weighing up to the fixation in $2 \mathrm{ml} 1 \mathrm{M}$ 
$\mathrm{HC10}_{4}$ ) was exactly recorded for each of the specimens by using a stopwatch. Mucosal histamine concentrations were determined in 10 biopsy specimens as described below and wet weight and histamine content of each sample were correlated to each other without correction for the time of cold ischaemia.

(3) The results of the second series of experiments led to a considerable search for endoscopic equipment and biopsy forceps which reduced the dispersion of sample weights and produced on the average larger biopsies. ${ }^{16}$ The Olympus GIF-Q instrument which by a smaller diameter and more flexibility reduced the number of patients needing premedication and the 'hot biopsy' forceps were finally selected. They were used in 54 patients (Table 1) in 1983 to reinvestigate the mean value and variation of specimen sizes by again constructing the histogram of the biopsy weights. Three specimens were analysed from each subject, a few biopsies were lost.

(4) Meanwhile the importance of cold ischaemia time for tissue histamine levels in human subjects was fully recognised. ${ }^{18}$ Thus in the fourth series of experiments in 1983 this time interval was limited to five minutes for each biopsy specimen. The relationship between weight of biopsy and mucosal histamine content was reinvestigated in 15 patients, six control subjects and nine patients with peptic ulcer, some of them again with concomitant diseases which may alter mucosal histamine concentrations (nos 50-60 in Table 1). Otherwise the same design was used in this study as in the second series of experiments.

\section{Relationship between cold ischaemia time and mucosal histamine content}

Two series of experiments were carried out in this part of the study from June to August 1976. They were carefully designed to measure as accurately as possible actual histamine levels which were defined as those existing in the human corpus mucosa in vivo exactly at the time of investigation and being not significantly altered by the time after the sample taking procedure.

(5) In the fifth trial three control subjects, three patients with duodenal ulcer and three with gastric carcinoma (nos 10-18 in Table 1) were recruited from all subjects admitted to endoscopy. To imitate a random assignment they were selected exactly in the sequence in which patients with these three diagnoses entered the hospital at this particular time of the year. From each of them nine biopsy specimens were taken for histamine assays and at least one for histology. The time from excision of biopsy up to its fixation in perchloric acid (cold ischaemia time) was prolonged for each of the samples consecutively from two minutes for the first one up to 20 minutes for the last specimen. A syringe needle was used to remove the biopsy from the forceps. After weighing the needle was used again to deposit the mucosal specimen about $0.5 \mathrm{~cm}$ above the surface of $2 \mathrm{ml} 1 \mathrm{M} \mathrm{HC10}_{4}$, on the inner wall of a test tube, then the biopsy was suspended in the fixation fluid by shaking it on a whirlmix apparatus. This technique was helpful in this series of experiments but essential in the sixth trial, where any contact of an instrument with the suspension fluid had to be carefully avoided to prevent errors in the weighing process. After withdrawal of the first two biopsies within a 30 second interval one person started the weighing procedure whereas another collected the remaining seven samples in further 30 second intervals. The cold ischaemia time for each of the biopsies (increasing by two minutes for each sample) was exactly recorded by using a separate stopwatch for each of the investigators.

(6) The aim of the sixth trial was to find out whether a plateau phase existed for actual histamine contents of human corpus mucosa after withdrawal which was long enough to permit an accurate estimation of stored and free histamine concentrations in routine endoscopy. Free histamine in plasma has a half-life time of about two minutes. ${ }^{26}$ If free histamine in the interstitial space had similar kinetics very short cold ischaemia times in the range of five to 10 seconds should be necessary for measuring actual histamine levels. This could be achieved only by immediately fixing biopsies in perchloric acid without interruption by the weighing procedure. Without change of the reference system - for example, protein, DNA - which introduced new problems in data interpretation, the difficulties could be solved only by a sophisticated gravimetric method which guaranteed the accuracy of the biopsy weights and avoided even 'negative' values for the mucosal specimens which sometimes were observed. Loss and trapping of aqueous vapour into or from the environment, respectively, had to be minimised and equilibrated. Endoscopy and weighing were carried out in the same room in this study.

To prepare seven second biposies, $2 \mathrm{ml}$ volumes of $1 \mathrm{M} \mathrm{HC10}_{4}$ were filled into five test tubes $(10 \mathrm{ml})$ with ground joint and ground glass stoppers the technician wearing plastic gloves throughout the experiment. One mol/litre $\mathrm{HClO}_{4}$ was found to be an eutropic solution which did not gain or lose weight in the tubes at $20^{\circ} \mathrm{C}$. After closing the tubes for one hour to obtain a constant vapour pressure they were opened for 10 seconds, closed again, carefully rubbed off with weighing paper and weighed with stoppers and fluid (approximately 20 g) on the analytical microbalance. In the following 
hour when endoscopy was carried out under routine conditions, one person opened the tubes sequentially for only about 10 seconds when the biopsy was taken and immediately deposited in the tube by a second person as described in series 6 . Any contact with the perchloric acid had to be absolutely avoided. The tube was closed and the biopsy washed into the fluid by using a whirlmix apparatus. After closing, the tube was placed in a test tube rack until the other four specimens were taken and processed in the same way. Then it was rubbed off again and weighed to calculate the weight of the biopsy (about 5-7 mg).

Two control experiments were necessary to test the reliability of the gravimetric method. (1) The relative accuracy of the weighing procedure was ascertained by comparing the mean values of biopsy weights of five seven second samples with those of five four minute samples which were obtained by the standard procedure described in Materials. They should be equal within the statistical limits given by the standard sample taking procedure. In training experiments before this study it was proven that the mean value of weights of at least five individual biopsies was equal to that of five others taken before or after them (within the statistical limits). (2) Five test tubes were processed exactly like those with seven second biopsies, but without actually adding tissue specimens. The mean of their weights before and after opening the tubes had to be equal (within the tight statistical limits of weighing) and hence could be used to correct the biopsy weights.

To compare the histamine contents of seven second biopsies with those of four minute biopsies three control subjects, two patients with duodenal ulcer and two with gastric ulcer (nos 19-25 in Table 1) instead of those with gastric cancer (not available at this time) were recruited from all subjects admitted to endoscopy in the same way as in trial 5 . From each of them 10 biopsies were taken for histamine assays, five for seven second biopsies and five for four minute biopsies (one condition of the experiment was carried out after the other, but the order in each pair was obtained by randomisation with random digits). At least one biopsy was taken for routine histology.

Regional distribution of mucosal histamine content In the seventh series of experiments a randomised controlled clinical trial was conducted in 24 patients (nos 26-49 in Table 1) including eight control subjects (age 46 years $(\tilde{\mathrm{x}})$, six men), eight patients with chronic duodenal ulcer (54 years $(\tilde{\mathrm{x}})$, five men) and eight patients with selective proximal vagotomy without pyloroplasty for duodenal ulcer ( 48 years $(\tilde{\mathbf{x}})$, seven men) 6-12 months after operation with- out symptoms and endoscopical evidence for recurrent ulceration. The aims of the trial were (a) to investigate mucosal histamine contents under optimum sample taking conditions (test for validation of previous findings,,$^{12}$ (b) to study mucosal histamine concentrations in several parts of the upper gastrointestinal tract and especially in the duodenum as the place of the lesion to examine the specificity of the previous findings in the corpus mucosa ${ }^{12}$ and (c) to test for the first time the influence of selective proximal vagotomy on the mucosal autocoid concentration which is said to be significantly involved in normal gastric acid secretion. ${ }^{27}$

The 24 patients were recruited from a current series of 374 endoscopies in February to April 1983 by a random design using a balanced random allocation with random digits. The selection from so many endoscopies was carried out by awaiting the next subject fitting to the next allocation group demanded by the randomisation procedure. In every subject informed consent was obtained for taking several biopsy specimens additional to the routine procedure. Then endoscopy was carried out establishing the final diagnosis. If this diagnosis fitted to that demanded in the random sequence of allocation, 16 biopsies were taken stepwise in the shortest possible time including four from the fundus, four from the corpus, four from the duodenal bulb and four from the antrum - according to the conditions described in materials. Two people were necessary to determine the weight of the biopsies within four to five minutes. Three biopsies were taken for histamine assays, one for histology. Histamine was determined in all samples of an individual patient at a single run in one particular day. Only one technician who was not informed about the diagnosis (blind study) analysed the specimens. Additional attributes of the patients were assessed as described in Methods.

Histamine was determined fluorometrically by a modified Shore ${ }^{28}$ procedure. After thawing the single biopsy was homogenised with an Ultraturrax homogeniser (microshaft TP $10 \mathrm{~N}$ ) and was added to the usual mixture of $n$-butanol, $\mathrm{NaOH}$ and $\mathrm{NaCl}$ in the first steps of the extraction method without centrifugation. Long and narrow Corning glass tubes (Sovirel ${ }^{\circledR}, 18 \times 180 \mathrm{~mm}, 25 \mathrm{ml}$, with screw cups) and a Heidolph shaking apparatus were used for this and the other two solvent partition steps, hence all centrifugations after the extractions proved to be unnecessary. This shortened the procedure considerably. The shaking time for sufficient extraction was 20 minutes in the first, two minutes in the second and six minutes in the third step of the method. Histamine ended in $3 \mathrm{ml} 0.1 \mathrm{M}$ $\mathrm{HCl}$ of which $2 \mathrm{ml}$ were mixed with $\mathrm{NaOH}$, 
o-phthaldialdehyde and $\mathrm{HCl}$, as described in the original assay, ${ }^{28}$ except that $0.1 \mathrm{ml} 0.05 \%$ o-phthaldialdehyde was added instead of $0.1 \mathrm{ml} 1 \%$ o-phthaldialdehyde to improve specificity while keeping accuracy because only very small amounts of tissue were used in this modification (cf. 18). Histamine was measured in a Zeiss spectrofluorometer PMQ 5 at an excitation wave length of $360 \mathrm{~nm}$ and emission wave length of $450 \mathrm{~nm}$ against a standard calibration curve ${ }^{18}$ and the mucosal histamine content was calculated according to Hesterberg $e t a^{18}$ and expressed in $\mu \mathrm{g}$ histamine dihydrochloride/g wet weight.

The recovery of histamine after extraction and condensation was assessed both by the external and internal standard method; $200 \mathrm{ng}$ authentic histamine was added to $2 \mathrm{ml} 1 \mathrm{M} \mathrm{HC10}{ }_{4}$ or biopsy homogenate. The recovery rate was found to be 78 $(62-102) \%$ in the first and $78(65-95) \%$ in the second method $(n=24, \bar{x}$ (range)). Two samples of a biopsy pool homogenate obtained from 52 patients with various gastric diseases were added to each run as quality controls, and the results were analysed by the double-standard control chart method. ${ }^{3}$

Clinical diagnoses and assessment of the patient's attributes including smoking habits, Visick grading after vagotomy and completeness of vagotomy were established by the same careful and extended techniques as described previously. ${ }^{1-3}$ Control subjects and several groups of patients with diseases of the upper gastrointestinal tract were defined according to Troidl et al. ${ }^{1}$ Control subjects were healthy with respect to stomach and duodenum.

For statistical analysis both the mean SD and median percentile system had to be applied depending on the frequency distributions. Because biopsies were taken several times from the same patient a two factorial analysis of variance with a repeated measurement design ${ }^{29}$ was conducted in the controlled clinical trial with regional distribution of histamine as factor A and status of disease (control, duodenal ulcer, selective proximal vagotomy) as factor B. A linear model was chosen for correlation and regression analysis. The sample correlation coefficient $r$ and the regression line were calculated by the method of least squares and $\mathrm{H}_{\mathrm{o}}$ for $\mathrm{r}$ was tested according to Snedecor and Cochrane $e^{30}$ using the Hewlett-Packard desk computer $9815 \mathrm{~A}$. In the two series of experiments the nominal p-value of the $\alpha$-error was not corrected for repeated significance testing.

\section{Results}

RELATIONSHIPS BETWEEN BIOPSY WEIGHT AND MUCOSAL HISTAMINE CONTENT

In contrast to accepted paradigms in histamine research $^{28} 3132$ the mucosal histamine content was no longer independent of the weight of a biopsy, but correlated either directly (in most cases) or indirectly with the other variable (Fig. 2, Table 2). Even more important than this correlation was the steepness of the regression lines (Fig. 2). Hence any mucosal histamine value could be arbitrarily 'determined' depending on the size of biopsy taken in a particular state of health and disease (mucosal thickness etc.).

Analysing the correlation between the two variables in relation to the variation of biopsy weights and cold ischaemia times (Table 2) as well as sex, age and disease (Table 1) only trends could be observed, probably due to the still relatively small sample size. The firmest correlation was found at the largest variation in biopsy weights including
Fig. 2 Relationship between weight of biopsy and mucosal histamine content. Histamine values and weights as single values obtained from single biopsy specimen. For further conditions see Table 2 and text in Materials and Methods.
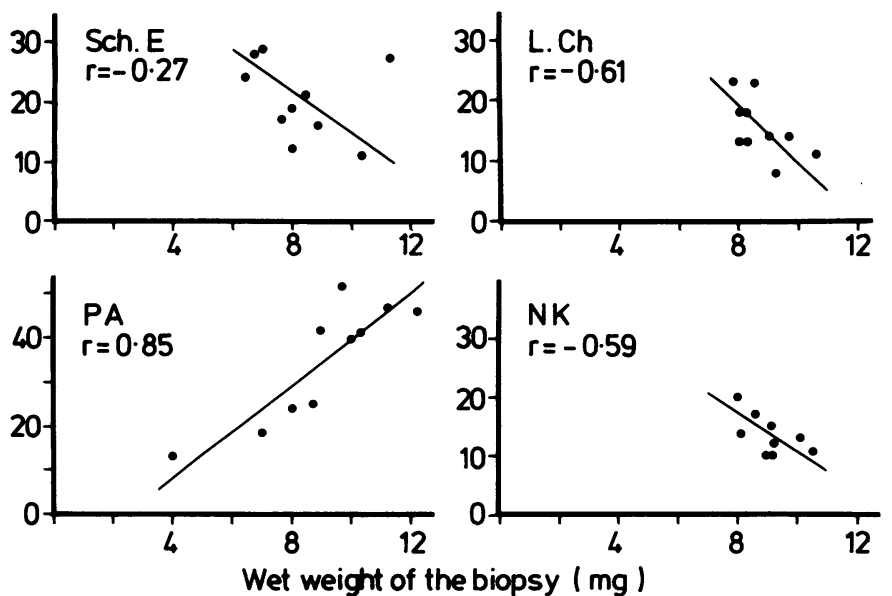
Table 2 Correlation coefficients and regression lines between weights of biopsies and mucosal histamine contents (ACMI biopsy forceps)

\begin{tabular}{|c|c|c|c|c|}
\hline \multirow{2}{*}{$\begin{array}{l}\text { Patient } \\
\text { Nodiag }\end{array}$} & \multicolumn{2}{|c|}{ Biopsy taking } & \multicolumn{2}{|c|}{ Relation between weight and $M H C$} \\
\hline & $\begin{array}{l}\text { Weight } \\
\text { (mg) }\end{array}$ & $\begin{array}{l}C I T \\
(\min )\end{array}$ & $\begin{array}{l}\text { Coeff of } \\
\text { correlation }\end{array}$ & Regression line \\
\hline $1 \mathrm{UV}$ & $8 \cdot 0-10 \cdot 5$ & $10-15$ & $-0.59 \mathrm{~ns}$ & $y=36.97-2.56 x$ \\
\hline CS & $7 \cdot 8-10 \cdot 6$ & $12-15$ & $-0.61 \mathrm{~ns}$ & $y=41.14-2.97 x$ \\
\hline CS & $6 \cdot 4-11 \cdot 3$ & $11-12$ & $-0.27 \mathrm{~ns}$ & $y=30.02-1.13 x$ \\
\hline UD & $4 \cdot 0-12 \cdot 2$ & $11-15$ & $0.85(\mathrm{p}<0.05)$ & $y=-9.12+4.90 x$ \\
\hline UV & $5 \cdot 2-8 \cdot 3$ & $10-15$ & $0.59 \mathrm{~ns}$ & $y=1.83+1.15 x$ \\
\hline $6 \mathrm{CS}$ & $1.9-9.4$ & $15-26$ & $0.94(\mathrm{p}<0.05)$ & $4 \cdot 23+6 \cdot 23 x$ \\
\hline 7 CS & $8 \cdot 0-11 \cdot 6$ & $11-19$ & $0.52 \mathrm{~ns}$ & $y=-12 \cdot 74+3.65 x$ \\
\hline CS & $9 \cdot 3-11 \cdot 9$ & $9-20$ & $0.55 \mathrm{~ns}$ & $y=-11 \cdot 77+2 \cdot 51 x$ \\
\hline 9 CS & $6 \cdot 1-10 \cdot 8$ & $10-19$ & $0.50 \mathrm{~ns}$ & $y=16 \cdot 24+3.02 x$ \\
\hline
\end{tabular}

Weights and histamine contents obtained from single biopsies. $\mathrm{n}=10$ per patient, weight and cold ischaemia time (CIT) are expressed as range. Diag $=$ diagnosis, coeff $=$ coefficient, MHC $=$ mucosal histamine content. Patients $1-9=1-9$ in Table 1. For further conditions see Material and Methods. ns=not significant.

those with the lowest absolute weights (patients no 4 and 6). In addition, sample taking with the longest cold ischaemia time (no 6) was connected with the firmest correlation whereas that with the shortest time was associated with the weakest (no 3). No trends, however, could be observed with sex, age or disease of the patients but a multifactorial relationship could not be excluded at all.

Three measures were taken, based on this analysis, to control the problem of varying biopsy weights as a rather unpredictable source of relevant bias. (a) A biopsy forceps was selected which produced considerably less variation in biopsy weights than the ACMI instrument (Fig. 1). (b) The cold ischaemia time was exactly measured for each biopsy taken and was limited to five minutes. Specimens undergoing a larger period were discarded (Table 3). (c) The mucosal histamine content of a single patient was always calculated as the mean of three values obtained from different specimens (cf. 1-3). In this way, histamine values based on mean biopsy weights were compared which differed from patient to patient by no more than $10 \%$ (section 3, controlled clinical trial).

As a result of the first two measures, only three of 15 patients or $20 \%$ showed coefficients of correlation $r \geqslant 0.5$ or $r \leqslant-0.5$ in the validation study (Table 3 ) as compared with eight of 10 subjects or $80 \%$ in the test study (Table 2 ). In addition, the regression lines were steeper in the first study than in the second one (greater coefficients in $\mathrm{x}$ in the regression equations), especially in the cases with larger biopsy weight variations. It is therefore concluded that the two factors, size of the biopsy and cold ischaemia time, may indeed be mainly responsible
Table 3 Correlation coefficients and regression lines between weights of biopsies and mucosal histamine content (hot biopsy forceps, cold ischaemia time $5 \mathrm{~min}$ )

\begin{tabular}{|c|c|c|c|c|}
\hline $\begin{array}{l}\text { Patient } \\
\text { No }\end{array}$ & Diag & $\begin{array}{l}\text { Biopsy weight } \\
(m g)\end{array}$ & $\begin{array}{l}\text { Relation between we } \\
\text { Coeff of correlation }\end{array}$ & eight and $M H C$ \\
\hline 1 & CS & $4 \cdot 9-6 \cdot 6$ & $0.54 \mathrm{~ns}$ & $y=13 \cdot 14+2 \cdot 27 x$ \\
\hline 2 & UD & $4 \cdot 4-8 \cdot 4$ & $0.36 \mathrm{~ns}$ & $y=16 \cdot 92+1 \cdot 17 x$ \\
\hline 3 & CS & $5 \cdot 1-8 \cdot 1$ & $0.00 \mathrm{~ns}$ & $y=32.95+0.13 x$ \\
\hline 4 & CS & $4 \cdot 9-7 \cdot 6$ & $-0.30 \mathrm{~ns}$ & $y=17.44-0.80 x$ \\
\hline 5 & CS & $6 \cdot 6-7 \cdot 6$ & $0.58 \mathrm{~ns}$ & $y=16 \cdot 37+6.09 x$ \\
\hline 6 & UD & $7 \cdot 1-8 \cdot 3$ & $0 \cdot 14 \mathrm{~ns}$ & $y=15.49+0.81 \times$ \\
\hline 7 & CS & $4 \cdot 7-7 \cdot 1$ & $0.22 \mathrm{~ns}$ & $y=23.85+0.61 \times$ \\
\hline 8 & UV & $3 \cdot 8-9 \cdot 0$ & $0.20 \mathrm{~ns}$ & $y=32.93+0.09 x$ \\
\hline 9 & UD & $2 \cdot 4-9 \cdot 4$ & 0.32 ns & $y=19.78+0.56 x$ \\
\hline 10 & RUD & $6 \cdot 8-7 \cdot 8$ & $-0 \cdot 28 \mathrm{~ns}$ & $y=40 \cdot 26-2 \cdot 13 x$ \\
\hline 11 & UD & $6 \cdot 4-7 \cdot 8$ & $0.17 \mathrm{~ns}$ & $y=17 \cdot 86+5 \cdot 21 \times$ \\
\hline 12 & UD & $2 \cdot 7-4 \cdot 2$ & $-0 \cdot 14 \mathrm{~ns}$ & $y=29 \cdot 04-1 \cdot 16 x$ \\
\hline 13 & UD & $3 \cdot 1-7 \cdot 4$ & $0.50 \mathrm{~ns}$ & $y=21 \cdot 20+1 \cdot 54 x$ \\
\hline 14 & CS & $3 \cdot 6-9 \cdot 7$ & $-0.26 \mathrm{~ns}$ & $y=40.92-1.00 x$ \\
\hline 15 & UD & $3 \cdot 2-7 \cdot 2$ & $0 \cdot 32 \mathrm{~ns}$ & $y=16.32+0.73 x$ \\
\hline
\end{tabular}

Weights and histamine contents obtained from single biopsies. $\mathrm{n}=10$ per patient, biopsy weight is expressed as range. Patients 50-64 inTable 1. For further conditions see Table 2.

for the bias observed and can be satisfactorily excluded by the measures taken in the validation study.

\section{RELATIONSHIP BETWEEN COLD ISCHAEMIA TIME \\ AND MUCOSAL HISTAMINE CONTENT}

The actual histamine content of mucosal biopsies remained constant for about four to five minutes only and decreased stepwise by about $40 \%$ (Fig. 3) within 20 minutes. The 'disappearance' rate depended on the status of health and disease. It was faster in control subjects than in duodenal ulcer patients (Fig. 4) whereas patients with gastric carcinoma showed a trend which was situated between those of the two other groups.

Mucosal histamine contents obtained after an extremely short ischaemia time differed from those after four to five minutes only by about $10 \%$ (Table 4). Biopsy weights, however, also tended to be $10 \%$ lower in specimens weighed by the gravimetric method than in those weighed by a routine procedure. As in comparisons of mean biopsy weights of 4 minute samples obtained from two consecutive sets of five biopsy specimens from the same corpus mucosa in the same sample taking process, the means did not systematically differ from each other this small difference between seven second and 4 minute biopsy weights may be a systematic error in the one or the other sample preparation procedure. If mucosal histamine contents were corrected for this factor they were equal in seven second and four minute biopsies. 
Fig. 3 Decrease of mucosal histamine content following sample taking as related to cold ischaemia time. Median (range) of nine patients (No 10-18 in Table 1). For further conditions see Materials and Methods.

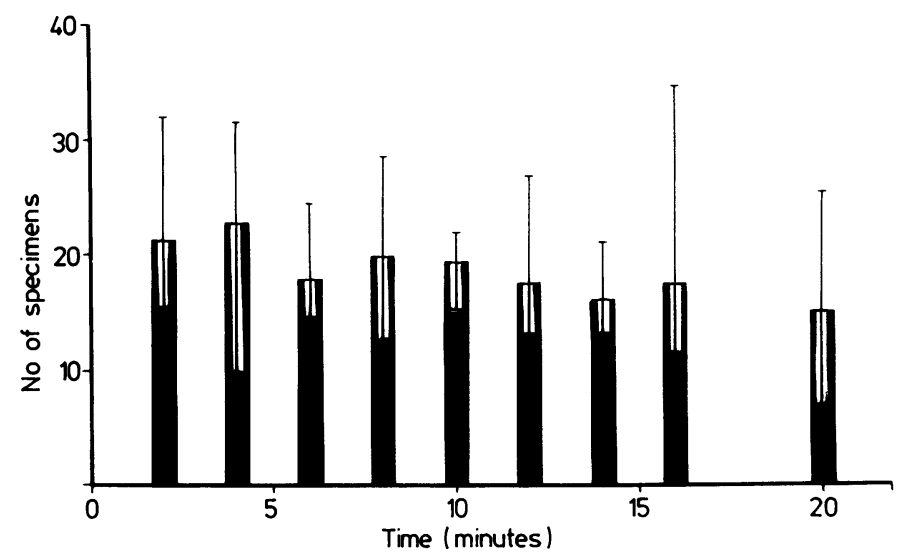

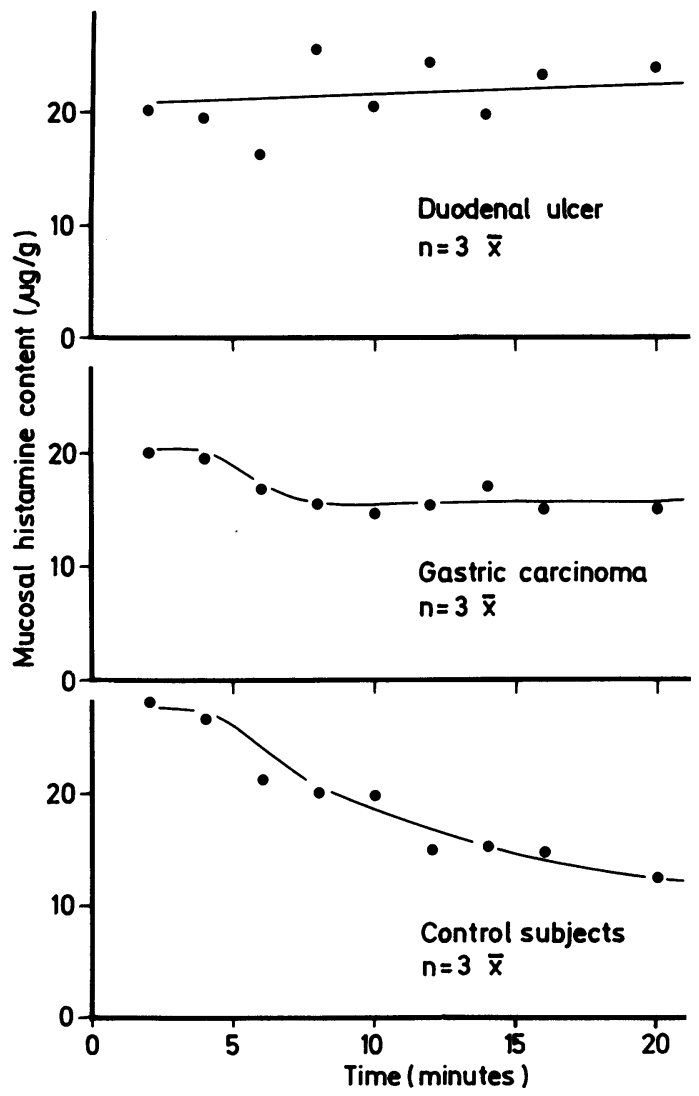

Fig. 4 Decrease of mucosal histamine content following sample taking as related to cold ischaemia time and the status of health and disease. Mean value of three individuals in each group of the patients (No 10-18 in Table 1). For further conditions see Materials and Methods.
MUCOSAL HISTAMINE CONTENT IN THE UPPER

GASTROINTESTINAL TRACT IN MAN

In a randomised controlled clinical trial mucosal histamine concentrations were obtained from 24 patients with an optimised sample taking procedure (Fig. 5). The medians in the eight control subjects were $37.5 \mu \mathrm{g} / \mathrm{g}$ for the fundic mucosa, 30 for the corpus, 25.5 in the antrum and 26 in the bulbus duodeni. At first glance, the variation of histamine values may be considered as relatively large, but calculation of the interquartile ranges easily showed that it was equal to that in well-designed animal experiments. $^{315}$ Compared with those in other human tissues all mucosal histamine levels have to be regarded as high tissue amine levels. ${ }^{8} 18$

In duodenal ulcer patients the mucosal histamine

Table 4 Mucosal histamine content following cold ischaemia time of 7 seconds or 4-5 minutes

\begin{tabular}{|c|c|c|c|c|c|}
\hline $\begin{array}{l}\text { Patient } \\
\text { No }\end{array}$ & Diag & $\begin{array}{l}7 \text { seconds } \\
\text { Weight } \\
\text { (mg) }\end{array}$ & $\begin{array}{l}M H C \\
(\mu g / g)\end{array}$ & $\begin{array}{l}4-5 \text { minutes } \\
\text { Weight } \\
\text { (mg) }\end{array}$ & $\begin{array}{l}M H C \\
(\mu g / g)\end{array}$ \\
\hline 1 & UD & $7 \cdot 8$ & $16 \cdot 5$ & $8 \cdot 5$ & $13 \cdot 5$ \\
\hline 2 & $\mathrm{CS}$ & $6 \cdot 5$ & $21 \cdot 8$ & $7 \cdot 2$ & $21 \cdot 4$ \\
\hline 3 & UV & $7 \cdot 2$ & $18 \cdot 7$ & $8 \cdot 4$ & $19 \cdot 5$ \\
\hline 4 & UV & $6 \cdot 5$ & $19 \cdot 2$ & $7 \cdot 7$ & $19 \cdot 0$ \\
\hline 5 & CS & $6 \cdot 4$ & $22 \cdot 5$ & $7 \cdot 2$ & $22 \cdot 5$ \\
\hline 6 & UD & $8 \cdot 8$ & $21 \cdot 7$ & 9.7 & $18 \cdot 6$ \\
\hline 7 & $\mathrm{CS}$ & $6 \cdot 8$ & $30 \cdot 6$ & $7 \cdot 1$ & $29 \cdot 5$ \\
\hline \multicolumn{2}{|c|}{$\begin{array}{l}\text { Total } \\
(\bar{x}(\text { range }))\end{array}$} & $\begin{array}{l}6 \cdot 8 \\
(6 \cdot 4-8 \cdot 8)\end{array}$ & $\begin{array}{l}21 \cdot 7 \\
(16 \cdot 5-30 \cdot 6)\end{array}$ & $\begin{array}{l}7 \cdot 7 \\
(7 \cdot 1-9 \cdot 7)\end{array}$ & $\begin{array}{l}19 \cdot 5 \\
(13 \cdot 5-29 \cdot 5)\end{array}$ \\
\hline
\end{tabular}

Weights and histamine contents obtained from single biopsies. Data are given as mean values of five estimations at 7 seconds and 4-5 minutes, diag $=$ diagnosis, $\mathrm{MHC}=$ mucosal histamine content . Patients 19-25 in Table 1. For further conditions see Materials and Methods. 
Fig. 5 Mucosal histamine concentrations in several gastric regions and the duodenum of control subjects, duodenal ulcer patients and patients 6-12 months after selective proximal vagotomy without pyloroplasty for duodenal ulcer. The single values in the figure are means of three measurements with three different biopsies. For further conditions see Materials and Methods. Analysis of variance: factor $A$ regional distribution $p<0.01$, factor $B$ disease $p<0.05$.

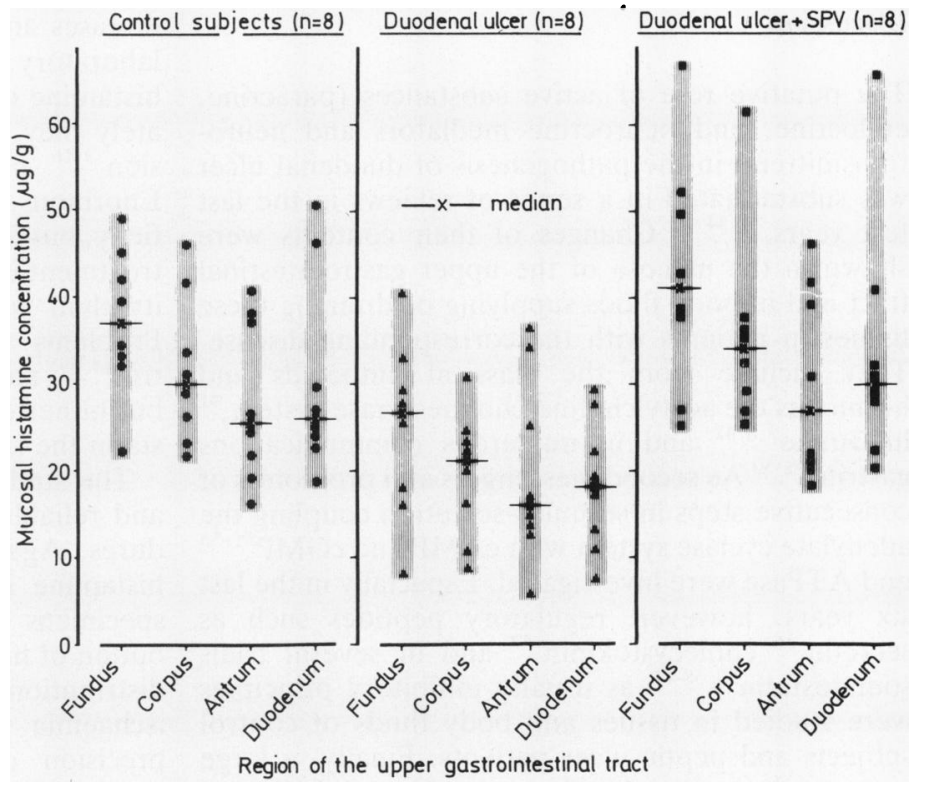

contents were considerably lower in all regions of the gastric mucosa and the duodenum. On the average, the changes were $-27 \%$ in the fundus, $-32 \%$ in the corpus, $-36 \%$ in the antrum and $-35 \%$ in the duodenum (Fig. 5). The reduction in corpus mucosal histamine content in duodenal ulcer patients as compared with control subjects was also shown in the other experimental series, such as in patients nos $10-18$ of Table $1(-31 \%)$ (Fig. 4), in patients $19-25(-34 \%)$ (Table 4$)$ and in patients 50-64 among whom the control subjects showed $29.8 \mu \mathrm{g} / \mathrm{g}$ histamine in the corpus mucosa and the duodenal ulcer patients $23.5 \mu \mathrm{g} / \mathrm{g}(-21 \%)$. Thus the changes of mucosal histamine in duodenal ulcer patients as compared with healthy controls could be reproduced several times over a period of 10 years ${ }^{1}$ both qualitatively and quantitatively provided that the histamine assay, sample taking and allocation of the patients to trial were tested and shown to be reasonably reliable.

Selective proximal vagotomy without pyloroplasty reversed the alterations of mucosal histamine levels in duodenal ulcer patients (Fig. 5). In the corpus mucosa this finding confirmed the previous observations after selective vagotomy with pyloroplasty. ${ }^{2}$ Surprisingly,' however, selective proximal vagotomy affected all parts of the upper gastrointestinal tract in the same way despite the fact that only the fundus-corpus areas were vagally denervated. Compared with duodenal ulcer patients the increase in mucosal histamine content was $+49 \%$ in the fundus, $+66 \%$ in the corpus, $+67 \%$ in the antrum and
$+76 \%$ in the duodenum. Such dramatic changes in tissue histamine concentrations have never been described in man.

Peden et $\mathrm{l}^{7}$ found an association between smoking and the decrease in fundic mucosal histamine concentrations in duodenal ulcer patients which to a large extent could explain the alterations of gastric histamine observed in peptic ulcer. Thus smoking habits, Visick grading and completeness of vagotomy (adequate vagotomy) ${ }^{33}$ were recorded and analysed in the clinical investigation and follow up. Smoking (at least five cigarettes/day) was recorded in three of the control subjects but in six of the duodenal ulcer patients supporting the findings of Peden et $a l^{7}$ After vagotomy five of the patients stopped smoking for the first four weeks. In the second follow up six to 12 months after vagotomy six of eight patients were again smokers (10-40 cigarettes/day). Despite this habit, the mucosal histamine levels in these patients were very high (Fig. 5) indicating an association, but no simple causal relationship between smoking and decreased histamine levels in duodenal ulcer patients.

In the eight patients after vagotomy three had Visick I, four Visick II and one Visick III. Two patients, one with Visick II and one with Visick III had an incomplete (Hollander-positive and Hollander-positive plus Bachrach-positive) vagotomy. Their corpus histamine content was only 22 and 28 $\mu \mathrm{g} / \mathrm{g}$, respectively supporting the hypothesis that a complete vagotomy is necessary to raise mucosal histamine concentrations. ${ }^{2}$ 


\section{Discussion}

The putative role of active substances (paracrine, endocrine, and neurocrine mediators and neurotransmitters) in the pathogenesis of duodenal ulcer was substantiated in a series of reviews in the last few years. ${ }^{1134-40}$ Changes of their contents were shown in the mucosa of the upper gastrointestinal tract and in body fluids supplying or draining these tissues in patients with the corresponding disease. They include from the classical autocoids and hormones the acetylcholine-cholinesterase system, ${ }^{41}$ histamine e $^{382}$ and in numerous communications gastrin. ${ }^{4-50}$ As second messengers and promoters of consecutive steps in stimulus-secretion coupling the adenylate cyclase system with cAMP and cGMP ${ }^{51-55}$ and ATPase were investigated. Especially in the last six years, however, regulatory peptides such as secretin, ${ }^{56}$ cholecystokinin, ${ }^{57}$ and in several trials somatostatin $^{50}{ }^{58-60}$ as usually inhibitory principles were studied in tissues and body fluids of control subjects and peptic ulcer patients. Finally, a large series of clinical biochemical research was dedicated to prostaglandins which exert a powerful protective effect on the gastroduodenal mucosa. ${ }^{39}{ }^{61-68}$

The many thoughtful hypotheses on messenger molecules in intercellular communication ${ }^{69}$ and peptic ulcer pathogenesis, however, were essentially weakened by regularly occurring contradictory findings about the changes of these active substances in tissues and body fluids (Table 5).

We became more and more convinced ${ }^{1316}$ (this article) that puzzling data and mental confusion were caused largely by insufficiencies of clinicalbiochemical trials which did not satisfactorily meet the criteria which have to be fulfilled in such a rather complex clinical situation. The studies must be designed: (1) with an assay for active substance(s) which is reliable (sensitive, specific, precise in the long run, accurate etc.) in health and various

Table 5 Contradictory findings on levels or synthesis of active substances in human gastric mucosa comparing duodenal ulcer patients with healthy controls

\begin{tabular}{|c|c|c|c|c|c|c|}
\hline \multirow{3}{*}{$\begin{array}{l}\begin{array}{l}\text { Active } \\
\text { substances }\end{array} \\
\text { Histamine }\end{array}$} & \multicolumn{6}{|c|}{ Mucosal levels or synthesis in DU patients } \\
\hline & Raised & & Equal & & Decreased & \\
\hline & Domschke & (13) & Peden & (7) & Troidl & (1) \\
\hline Gastrin & Creutzfeldt & (43) & Hughes & (46) & Malmstrom & (44) \\
\hline (G17 and G34) & $\begin{array}{l}\text { Sumii } \\
\text { Sumii }\end{array}$ & $\begin{array}{l}(48) \\
(50)\end{array}$ & & & Barbara & (47) \\
\hline Somatostatin & McIntosh & (60) & Creutzfe & At (59) & $\begin{array}{l}\text { Chayrialle } \\
\text { Sumii }\end{array}$ & $\begin{array}{l}(58) \\
(50)\end{array}$ \\
\hline $\begin{array}{l}\text { Prostaglandin } \\
\mathrm{E}_{2}\end{array}$ & Aly & (70) & Schlegel & (66) & Konturek & (67) \\
\hline
\end{tabular}

diseases and in clinical conditions, not only in the laboratory. These requirements were tested for histamine in gastric mucosal biopsies ${ }^{3}$ but unfortunately they were published in detail only for precision, ${ }^{316}$ not yet for specificity and accuracy. ${ }^{71}$ Enormous problems arose in demonstrating specificity, but finally it was shown that diseases and drug treatment interfered more with the tests on specificity than with the specificity of the assay itself. ${ }^{71}$ Problems with the reliability of assays for gastrin $^{44} 49$ and prostaglandins ${ }^{39} 68$ were recognised, but hitherto not sufficiently settled and for somatostatin the situation seems even worse.

The studies must be designed ${ }^{2}$ with well defined and reliable sample taking and preparation procedures. Again, these requirements were tested for histamine in great detail including weight of the specimens (this communication), horizontal distribution of histamine in the corpus mucosa,${ }^{16}$ vertical distribution of histamine within the mucosa,${ }^{16}$ cold ischaemia time (this communication), within-day precision of sample taking ${ }^{23}$ and day to day precision of sample taking. ${ }^{2} 3$ Perchloric acid extraction for free histamine was complete. ${ }^{28}$ Hence sample taking problems were settled for histamine but are still a matter of debate for gastrins ${ }^{404849}$ and prostaglandins and are unsettled for somatostatin. 3968 In addition, the problem of cold ischaemia time was already strongly emphasised by Feldberg and Schilf ${ }^{31}$ and several other groups (see reference 3) for histamine and by Gershon ${ }^{37}$ for serotonin. For peptide hormones and prostaglandins it seems highly relevant but the authors have completely neglected this problem in their communications. All discrepancies between the histamine studies could be explained simply by different effects of cold ischaemia time on mucosal amine concentrations in duodenal ulcer patients and control subjects (Fig. 6).

The studies must be designed ${ }^{3}$ as controlled clinical trials. Active substances in the gastroduodenal mucosa are regulated by a vast number of influences which are time dependent such as the natural history and time-course of the ulcer itself and which are defined by genetic and environmental factors ${ }^{3} 18$ including habits of patients (smoking, alcohol, and drugs). ${ }^{72}$ Thus any kinds of changes in mediator concentrations can be produced in clinical studies as artefacts if these prognostic factors are not fairly equally distributed. Histamine, in addition, is localised in mast cells which participate in immunological processes. Single prognostic factors have been investigated in trials on active substances and peptic ulcer, such as histamine, ${ }^{7}$ gastrin ${ }^{73}$ and somatostatin. ${ }^{74}$ As yet no multivariate analysis has been conducted and only limited consequences were 


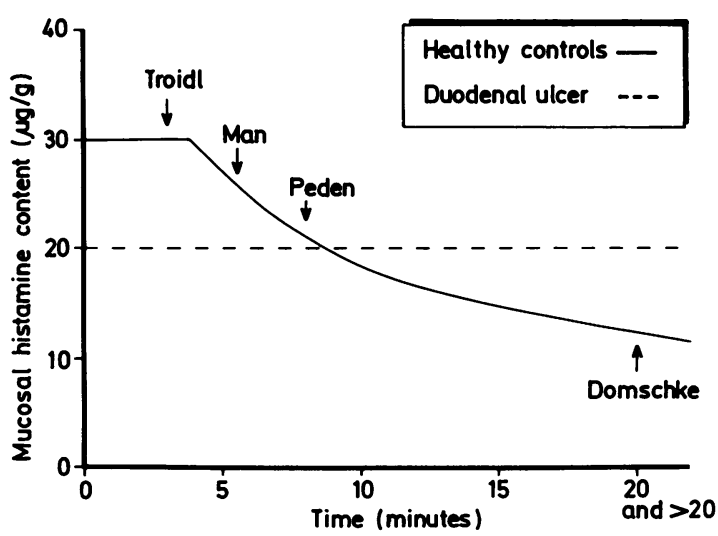

Fig. 6 Differences in gastric mucosal histamine levels between duodenal ulcer patients and healthy controls obtained in several studies and explained by different sample taking (time of cold ischaemia). Time course constructed from Fig. 4, differences between DU patients and controls (in per cent) taken from the references in Table 5. For further information on Domschke's trial see Rohde et al. ${ }^{16}$

drawn from epidemiological findings in designing studies on peptic ulcer pathogenesis, except for histamine ${ }^{1-3}$ (this communication). The reason for this regrettable situation can easily be found in this article: hundreds of patients admitted to the endoscopical unit were necessary to select the rather small number of 24 patients by strict randomisation. We have to think about other study designs which make reliable trials on peptic ulcer pathogenesis more feasible.

The controlled clinical trial in this communication confirmed the previous findings on decreased histamine levels in the corpus mucosa of duodenal ulcer patients and increased contents after vagotomy. ${ }^{12}$ All these changes were, however, not specific for the acid producing part of the stomach, but occurred in all gastric regions and in the duodenal bulb as well. Hence these findings did not support the previous hypothesis of an increased histamine release by an increased vagal drive ${ }^{2}$ in duodenal ulcer disease inducing gastric hyperchlorhydria but also did not contradict it. The uniform biochemical changes pointed to a more general alteration in histamine storage in this disorder than only to a defect in the oxyntic mucosa. Several hypotheses could be developed. (1) The alterations of histamine content in the corpus mucosa were induced directly by selective proximal vagotomy, in the antrum and duodenum indirectly by inhibition of $\mathrm{H}(+)$-ion back-diffusion (partial Davenport hypothesis). (2) The alterations of histamine content in duodenal ulcer disease were not the cause but the consequence of hyperchlorhydria and hypersecretion followed by an increased $\mathrm{H}(+)$-ion back-diffusion (Davenport hypothesis). (3) The alterations of histamine content were triggered by mast cell receptors which were regulated by the intragastric $\mathrm{pH}$ (effect contrary to that observed at .G-cells). (4) The alterations of histamine content were caused by trophic effects on mast cell proliferaiton induced by an augmented release of gastrin following vagotomy. (5) Finally, an interesting new hypothesis was developed ${ }^{22}{ }^{23}$ which offered the possibility of new relevant experiments. Vagal reflexes with afferent fibres coming from the oxyntic mucosa stimulate histamine release in duodenal ulcer patients by efferent peptidergic neurons to all parts of the stomach and especially to the duodenum where the ulcer lesion is situated. This hypothesis could explain the effect of selective proximal vagotomy and seemed reasonable since substance $P$, neurotensin and somatostatin were all shown to be potent histamine releasers from mast cells (for review see reference 9). In addition, the Davenport hypothesis and to some extent also the other ones were not supported by the recent finding that omeprazole, the potent inhibitor of gastric ATP-ase, reduced the peak acid output by $95 \%$, but did not change the corpus mucosal histamine levels ${ }^{20}$ in duodenal ulcer patients.

This study is dedicated to Professor Horst Hamelmann on the occasion of his 60th birthday. It was supported by a grant of Deutsche Forschungsgemeinschaft (Lo 199/12-5). The improvement of the English by $\mathrm{M}$ Ennis (PhD) and the technical assistance of Traudl Acker and Evelyn Thursar is greatly appreciated.

\section{References}

1 Troidl H, Lorenz W, Rohde H, Häfner G, Ronzheimer M. Histamine and peptic ulcer: a prospective study of mucosal histamine concentration in duodenal ulcer patients and in control subjects suffering from various gastrointestinal diseases. Klin Wochenschr 1976; 54: 947-56.

2 Troidl H, Rohde H, Lorenz W, Häfner G, Hamelmann H. Effect of selective gastric vagotomy on histamine concentration in gastric mucosa of patients with duodenal ulcer. Br J Surg 1978; 65: 10-6.

3 Lorenz W, Troidl H, Barth H, Rohde H. Histamine, gastric secretion and peptic ulcer disease: an attempt to define special sources of error and problems in clinicalbiochemical trials. In: Creutzfeldt W, ed. Cimetidine, Amsterdam and Oxford: Excerpta Medica, 1978: 6-34 
4 Man WK, Saunders JH, Ingoldby C, Spencer J. Effect of pentagastrin on histamine output from the stomach in patients with duodenal ulcer. Gut 1981; 22: 916-22.

5 Man WK, Saunders JH, Ingoldby C, Spencer J. Effect of cimetidine on the amounts of histamine in the gastric mucosa of patients with gastric or duodenal ulcers. Gut 1981; 22: 923-6.

6 Peden NR, Boyd EJS, Shepherd DM, Wormsley KG. Histamine, gastric secretion and duodenal ulcer. Hepatogastroenterol 1982; 29: 88.

7 Peden NR, Callachan H, Shepherd DM, Wormsley KG. Gastric mucosal histamine and histamine methyltransferase in patients with duodenal ulcer. Gut 1982; 23: $58-62$.

8 Lorenz W, Thon K, Barth H, Neugebauer E, Reimann $\mathrm{HJ}$, Kusche J. Metabolism and function of gastric histamine in health and disease. J Clin Gastroenterol 1983; 5 (suppl 1): 37-56.

9 Lorenz W, Röher HD, Doenicke A, Ohmann Ch. Histamine release in anaesthesia and surgery: a new method to evaluate its clinical significance with several types of causal relationship. Clin Anaesthesiol 1984; 2: 403-26.

10 Barth H, Troidl H, Lorenz W, Rohde H, Glass R. Histamine and peptic ulcer disease: histamine methyltransferase activity in gastric mucosa of control subjects and duodenal ulcer patients before and after surgical treatment. Agents Actions 1977; 7: 75-9.

11 Baron JH. Current views on pathogenesis of peptic ulcer. Scand J Gastroenterol 1982; 17 (suppl 80): 1-10.

12 Lorenz W, Doenicke A. Histomine release in clinical conditions. Mount Sinai J Med 1978; 45: 357-86.

13 Domschke W, Subramanian M, Mitznegg P, Baenkler HW, Domschke S, Wünsch E. Gastric mucosal histamine in duodenal ulcer patients: release by secretin. Acta Hepatogastroenterol (Stuttg) 1978; 24: 444-6.

14 Subramanian N, Mitznegg P, Domschke W. A rapid and sensitive enzymatic-isotopic method for routine assay of histamine in blood, plasma and biopsy tissue: re-evaluation. Acta Hepatogastroenterol (Stuttg) 1978; 25: $456-8$

15 Lorenz W, Parkin JV, Rohde $\mathrm{H}$ et al. Histamine in gastric secretory disorders: the relevance of the mucosal histamine content and the origin of histamine in gastric aspirate. In: Konturek SJ, Domschke W, eds. Gastric secretion - basic and clinical aspects. Stuttgart and New York: Thieme, 1981: 29-51.

16 Rohde H, Lorenz W, Troidl H, Reimann HJ, Häfner $G$, Weber D. Histamine and peptic ulcer: Influence of sample-taking on the precision and accuracy of fluorometric histamine assay in biopsies of human gastric mucosa. Agents Actions 1980; 10: 175-85.

17 Rohde H, Lorenz W, Troidl H, Thon K, Weber D. Influence of various conditions of sample-taking on the accuracy of histamine assays in human gastric mucosa. Acta Hepatogastroenterol (Stuttg) 1982; 29: 88.

18 Hesterberg R, Sattler J, Lorenz W et al. Histamine content, diamine oxidase activity and histamine methyltransferase activity in human tissues: fact or fiction? Agents Actions 1984; 14: 325-34.

19 Mendez-Diaz R, Man WK, Savasan MK, Boesby S, Spencer $\mathbf{J}$. The role of endogenous histamine store in gastric acid secretion. Br J Surg 1982; 69: 678.

20 Man WK, Spencer J, Collin NA, Thompson JN, Baron $\mathrm{JH}$. Effects of omeprazole on gastric mucosal histamine and histamine methyltransferase, and on histamine release. Acta Hepatogastroenterol (Stuttg) 1984; 31: 98.

21 Lorenz W, Mohri K, Reimann HJ, Troidl H, Rohde $\mathrm{H}$, Barth $\mathrm{H}$. Intramucosal mechanisms: relevance of the mast cell concept. In: Holtermüller $\mathrm{KH}$, Malagelada JR, eds. Advances in ulcer disease. Amsterdam and Oxford: Excerpta Medica, 1981: 176-94.

22 Thon KP, Lorenz W, Ohmann Ch, Weber D, Stöltzing H. Alterations of histamine storage in stomach and duodenum by SPV: a new mechanism involving afferent vagal fibers? Acta Hepatogastroenterol (Stuttg) 1984; 31: 99.

23 Thon KP, Lorenz W, Weber D, Stöltzing H, Ohmann $\mathrm{Ch}$. Veränderungen der Histaminspeicherung im Magen und Duodenum nach selektiv-proximaler Vagotomie. Langenbecks Arch Klin Chir (suppl). Chirurg Forum 1984: 135-9.

24 Sattler J, Hesterberg R, Schmidt U, Crombach M, Lorenz W. Inhibition of human and canine intestinal DAO by drugs used in an intensive care unit: relevance for clinical side-effects?. Agents Actions 1985; 16: 91-4.

25 Barth H, Kapp B, Crombach M, Priesack W, Lorenz W. Histamine storage and metabolism of human liver in disorders of the biliary tract. Agents Actions 1980; 10: $101-4$

26 Lorenz W, Doenicke A, Schöning B, Ohmann Ch, Grote B, Neugebauer E. Definition and classification of the histamine-release response to drugs in anaesthesia and surgery: studies in the conscious human subject. Klin Wochenschr 1982; 60: 896-913.

27 Lorenz W, Troidl H, Barth $\mathrm{H}$ et al. Stimulus-secretion coupling in the human and canine stomach: role of histamine. In: Case RM, Goebell H, eds. Stimulussecretion coupling in the gastrointestinal tract. Lancaster: MTP Press, 1976: 177-90.

28 Shore PA, Burkhalter A, Cohn VH jr. A method for the fluorometric assay of histamine in tissues. $J$ Pharmacol Exp Ther 1959; 127: 182-7.

29 Bortz J. Lehrbuch der Statistik für Sozialwissenschaftler. Berling-Heidelberg: Springer, 1977: 414-40.

30 Snedecor GW, Cochran WG. Statistical methods. Ames: Iowa State University Press, 1978: 172-88.

31 Feldberg W, Schilf E. Histamin. Seine pharmakologische Bedeutung für die Humoralphysiologie. Berlin: Springer, 1980: 24-71.

32 Code CF, McIntire FC. Quantitative determination of histamine. Methods Biochem Anal 1956; 3: 49-95.

33 Faber RG, Russell RCG, Parkin JV, Whitfield P, Hobsley M. The predictive accuracy of the postvagotomy insulin test: a new interpretation. Gut 1975; 16: $337-42$.

34 Konturek St J. Vagal and hormonal influences on gastric secretion in duodenal ulcer disease. Klin Wochenschr 1976; 54: 903-10.

35 Arnold R, Lankisch PG. Somatostatin and the gastrointestinal tract. Clin Gastroenterol 1980; 9: 733-53.

36 Sagor GR, Baron JH, Bloom SR, Polak JM. The clinical relevance of regulatory peptides. In: Russell RCG, ed. Regulatory peptides Edinburgh: Churchill 
Livingstone 1982: 1-25.

37 Gershon MD. Serotonergic neurotransmission in the gut. Scand J Gastroenterol 1982; 17 Suppl 71: 27-41.

38 Bishop AE, Ferri G-L, Probert L, Bloom SR, Polak JM. Peptidergic nerves. Scand J Gastroenterol 1982; 17: suppl 71: 43-59.

39 Johansson C, Bergström S. Prostaglandins and protection of the gastroduodenal mucosa. Scand J Gastroenterol 1982; 17: suppl 77: 21-46.

40 Creutzfeldt W. Gastrointestinal peptides - role in pathophysiology and disease. Scand J Gastroenterol 1982; 17: suppl 77: 7-20.

41 Hansen WE, Bertl S. Determination of acetylcholinesterase and pseudo-cholinesterase in gastrointestinal biopsy tissue. J Clin Chem Clin Biochem 1982; 20: 69-74.

42 Mohri K, Reimann H-J, Lorenz W, Troidl H, Weber D. Histamine content and mast cells in human gastric mucosa. Agents Actions 1978; 8: 372-5.

43 Creutzfeldt W, Arnold R, Creutzfeldt C, Track NS. Mucosal gastrin concentration, molecular forms of gastrin, number and ultrastructure of G-cells in patients with duodenal ulcer. Gut 1976; 17: 745-54.

44 Malstrøm J, Stadil F, Rehfeld JF. Concentration and component pattern in gastric, duodenal, and jejunal mucosa of normal human subjects and patients with duodenal ulcer. Gastroenterology 1976; 70: 697-703.

45 Malstrøm J, Stadil F. Christensen KC. Effect of truncal vagotomy on gastroduodenal content of gastrin. $\mathrm{Br} J$ Surg 1977; 64: 34-8.

46 Hughes WS, Snyder N, Hernandez A. Antral gastrin concentration in upper-gastrointestinal disease. Dig Dis 1977; 22: 201-8.

47 Barbara L, Biasco G, Saleva M et al. Antral G-cells and mucosal gastrin concentration in normal subjects and in patients with duodenal ulcer. Adv Exp Med Biol 1978; 106: $97-105$.

48 Sumii K, Yokoyama Y, Matsui Y et al. The increased antral gastrin content and its release in response to test meal in patients with duodenal ulcer. Hiroshima J Med Sci 1979; 28: 221-7.

49 Calam J, Dockray J, Walker R, Tracy HJ, Owens D. Molecular forms of gastrin in peptic ulcer: comparison of serum and tissue concentrations of G 17 and G 34 in gastric and duodenal ulcer subjects. Eur J Clin Invest 1980; 10: 241-7.

50 Sumii K, Fukushima T, Hirata $\mathrm{K}$ et al. Antral gastrin and somatostatin concentrations in peptic ulcer patients. Peptides 1981; 2: suppl 2: 281-3.

51 Ruoff HJ, Painz B, Becker M, Rack M, Sewing KF, Malchow $H$. Adenylate cyclase in human gastric mucosa: its activation by histamine in morphologically different biopsy specimens. Klin Wochenschr 1979; 57: 725-30.

52 Aadland E, Torjesen P, Berstad A, Ruoff HJ. Adenylate cyclase activity in gastric mucosal biopsies and cAMP in gastric juice before and after cimetidine treatment in healthy subjects. Scand J Gastroenterol 1981; 16: 615-23.

53 Mooney PA, Walters JM, McCarthy CF, O'Donnell $\mathrm{JM}$. The effect of cimetidine on cyclic nucleotides in human gastric mucosa. Br J Clin Pharmacol 1981; 12:
161-4.

54 Becker $\mathrm{M}$, Ruoff $\mathrm{HJ}$. Inhibition by prostaglandin $\mathrm{E}_{2}$, somatostatin and secretin of histamine-sensitive adenylate cyclase in human gastric mucosa. Digestion 1982; 23: 194-200.

55 Mooney PA, Walters JM, Kelly BM, McCarthy CF, O'Donnell JM. Effect of cimetidine on histamineactivated ATPase in human gastric mucosa. Digestion 1982; 25: 173-9.

56 Koizumi F, Ishimori A, Nakanome $\mathrm{C}$ et al. Mucosal secretin of the duodenum in peptic ulcer disease. Tohoku J Exp Med 1981; 133: 301-5.

57 Kataoka S. Cholecystokinin-like activity in the duodenal mucosa of duodenal ulcer patients. Gut 1982; 23: 390-7.

58 Chayrialle JAP, Descos F, Bernard C, Martin A, Barbe C, Pastensky C. Somatostatin in mucosa of stomach and duodenum in gastroduodenal disease. Gastroenterology 1978; 75: 13-9.

59 Creutzfeldt W, Arnold R. Somatostatin and the stomach: exocrine and endocrine aspects. Metabolism 1978; 27 suppl: 1309-15.

60 McIntosh C, Arnold R, Bothe E, Becker H, Köbberling $\mathrm{J}$, Creutzfeldt W. Gastrointestinal somatostatin: extraction and radioimmunoassay in different species. Gut 1978; 19: 655-63.

61 Peskar BM, Peskar BA. On the metabolism of prostaglandins by human gastric fundus mucosa. Biochim Biophys Acta 1976; 424: 430-8.

62 Peskar BM. On the synthesis of prostaglandins by human gastric mucosa and its modification by drugs. BiochimBiophys Acta 1977; 487: 307-14.

63 Bennett A, Murray JG, Wyllie JH. Occurrence of prostaglandin $E_{2}$ in the human stomach and a study of its effects on human isolated gastric muscle. $\mathrm{Br} J$ Pharmacol 1968; 32: 339-49.

64 Huisdale IG, Engel JJ, Wilson DE. Prostaglandin $\mathrm{E}_{2}$ in peptic ulcer disease. Prostaglandins 1974; 6: 459-500.

65 Baker R, Jaffe BM, Venables CW. Endogenous prostaglandins in peptic ulcer disease. Gut 1979; 20: 394-9.

66 Schlegel W, Wenke K, Dollinger HC, Raptis S. Concentrations of prostaglandin A-, E- and F-like substances in gastric mucosa of normal subjects and of patients with various gastric diseases. Clin Sci Mol Med 1977; 52: 255-8.

67 Konturek St J, Obtulowicz W, Sito E, Olesky J, Wilkon S, Kiec-Dembinska A. Distribution of prostaglandins in gastric and duodenal mucosa of healthy subjects and duodenal ulcer patients: effects of aspirin and paracetamol. Gut 1981; 22: 283-9.

68 Wright JP, Young GO, Klaff LJ, Weers LA, Price STK, Marks IN. Gastric mucosal prostaglandin E levels in patients with gastric ulcer disease and carcinoma. Gastroenterology 1982; 82: 263-7.

69 Roth J, Le Roith D. Evolutionary origins of intercellular communication: implications for human biology. In: Hirschowitz BI and Spenney JG, eds. Receptors and the upper GI tract. New York: Advanced Therapeutics Communications; 1983: 1-10.

70 Aly A, Green K, Johansson C. Prostaglandin synthesis in gastric and duodenal mucosa in man. Scand $J$ 
Gastroenterol 1981; 16: 1099-104.

71 Thon KP. Clinical relevance and reliability of the histamine determination in the upper GI tract in duodenal ulcer patients and following selective proximal vagotomy. University of Marburg/Lahn: Habilitationthesis, 1984: 1-169.

72 McCloy RF, Greenberg GR, Baron JH. Duodenal pH in health and duodenal ulcer disease: effect of a meal,
Coca-Cola, smoking, and cimetidine. Gut 1984; 25: 386-92.

73 Uvnäs-Wallensten $\mathrm{K}$, Palmblad J. Effect of food deprivation (fasting) on plasma gastrin levels in man. Scand J Gastroenterol 1980; 15: 187-91.

74 Koop H, Schwab E, Arnold R, Creutzfeld W. Effect of food deprivation on rat gastric somatostatin and gastrin release. Gastroenterology 1982; 82: 871-6. 